\title{
CRESCIMENTO INICIAL DE QUATRO ESPÉCIES FLORESTAIS NATIVAS EM ÁREA DEGRADADA COM DIFERENTES NÍVEIS DE CALAGEM E DE ADUBAÇÃO
}

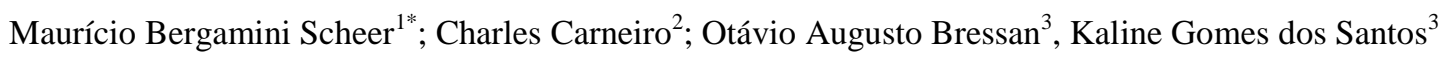 \\ ${ }^{1}$ SANEPAR - Assessoria de Pesquisa e Desenvolvimento, Curitiba, Paraná, Brasil - mauriciobs@ @anepar.com.br \\ ${ }^{2}$ SANEPAR - Unidade de Gestão de Resíduos Sólidos, Curitiba, Paraná, Brasil - charlesc@ sanepar.com.br \\ ${ }^{3}$ Grupo Yser, São Paulo, São Paulo, Brasil - kalinegomes@live.com, oabressan@ gmail.com
}

Recebido para publicação: 01/07/2015- Aceito para publicação: 28/07/2017

\begin{abstract}
Resumo
O presente trabalho teve o objetivo de avaliar o crescimento inicial de mudas de Schinus terebinthifolius, Gymnanthes klotzschiana, Luehea divaricata e Lafoensia pacari em área degradada (usada como área empréstimo), submetidas a três níveis de fertilizante NPK 5-20-10 (0, 300 e 500 g por cova) e dois níveis de calagem (calcário dolomítico com $75 \%$ de PRNT) (250 e $500 \mathrm{~g}$ por cova). As medições das alturas e diâmetros à altura da base foram realizadas após dois anos do plantio no campo. A dose de $250 \mathrm{~g}$ de calcário por cova possibilitou, na maioria dos casos, o melhor desenvolvimento das espécies utilizadas no experimento. A dose de $500 \mathrm{~g}$ de calcário, em algumas situações, afetou o crescimento das plantas, provavelmente em função do aumento excessivo de $\mathrm{pH}$ e consequente diminuição da disponibilidade de micronutrientes e/ou pelo desbalanço nutricional ocasionado. A adubação com fertilizante NPK influenciou de forma distinta no crescimento de cada espécie, apresentando respostas diferenciadas com relação às dosagens utilizadas, de acordo com as necessidades nutricionais da espécie. A espécie que apresentou melhor crescimento sob as condições do experimento, foi Schinus terebinthifolius, com alturas e diâmetro estatisticamente superiores as demais.

Palavras chave: Áreas de empréstimo; recuperação; restauração; fertilização; mudas florestais.
\end{abstract}

\begin{abstract}
Initial growth of four native species in degraded areas with different levels of NPK and liming. This study aimed to evaluate the initial growth of seedlings of Schinus terebinthifolius, Gymnanthes klotzschiana, Luehea divaricata and Lafoensia pacari in a degraded area, as response to three levels of NPK 5-20-10 fertilizer ( 0,300 and $500 \mathrm{~g}$ per pit) and two levels of liming (dolomitic limestone with $75 \%$ PRNT) (250 and $500 \mathrm{~g}$ per pit). When the plants reach two years in the field, individuals were measured to obtain the height and diameter at the base. The dose of $250 \mathrm{~g}$ of limestone per pit allowed the greatest growth in height and diameter for the species used in the experiment. The dose of $500 \mathrm{~g}$ of limestone, in many cases, affected plant growth, probably due to the excessive increase of $\mathrm{pH}$ and consequent decreased availability of metallic micronutrients or nutritional imbalance caused. Fertilization with NPK fertilizer acted differently in the growth of each species, showing different responses with respect to the dosages used, according to the nutritional needs of the species. Under the conditions of the experiment, Schinus terebinthifolius presented the highest growth rates for height and diameter.

Keywords: Borrow pit; recovery; restoration; fertilization; forest seedlings.
\end{abstract}

\section{INTRODUÇÃO}

Obras de engenharia e mineração geralmente requerem material (argilas) de "áreas de empréstimo", nas quais há a remoção da vegetação e da camada superficial do solo (ALVES et al. 2012) (horizontes superficiais e subsuperficiais), muitas vezes ficando exposto o horizonte $\mathrm{C}$ e/ou regolito, em situações diferentes da condição geomorfológica original, praticamente estéreis e com condições de regeneração extremamente limitadas. Desconsiderando a devolução de "topsoil" (ou terravegetal/horizonte A), geralmente feita sem práticas adequadas de manejo dos horizontes superficiais estocados para posterior recobrimento do local e de controle de processos de erosão (escoamento superficial), no substrato remanescente, a disponibilidade de matéria orgânica, porosidade, microbiota, propágulos e nutrientes é desprezível, havendo mudanças na acidez e estrutura do substrato, mudanças no microclima e limitação do desenvolvimento de plantas.

FLORESTA, Curitiba, PR, v. 47, n. 3, p. 279 - 287, jul. / set. 2017.

Scheer, M. B. et al.

ISSN eletrônico 1982-4688

DOI: $10.5380 /$ rf.v47i1.41973 
Apesar do conhecimento sobre as demandas nutricionais de espécies nativas e seu desenvolvimento para a recuperação de áreas degradadas, áreas ciliares, entre outras finalidades, ser de fundamental importância (COSTA FILHO, 2010), há ainda uma carência de informações. São ainda mais raros experimentos em escala de campo, onde se tem resultados envolvendo ações de diversos fatores ambientais que, embora não se possa ter adequado controle, tem o potencial de promover respostas mais próximas do que ocorre na aplicação prática.

Schinus terebinthifolius Raddi, popularmente conhecida como aroeira, família Anacardiaceae, é uma espécie arbórea de rápido crescimento, perenifólia, heliófita e pioneira, comum em beiras de rios, córregos e em várzeas úmidas de formações secundárias, contudo, crescendo também em terrenos secos e pobres (LORENZI, 2002). Em compilação de pesquisas fitossociológicas no Paraná, essa espécie consta como a terceira espécie arbórea mais abundante para a região da Floresta Ombrófila Mista Aluvial (SCHEER; BLUM, 2011). Chiamolera et al. (2011) afirmam que a aroeira tem comportamento de espécie secundária, mas com alta plasticidade, podendo se adequar a condições com maior disponibilidade de luz. Com frutos amplamente disseminados por pássaros, possui uma boa regeneração natural. Geralmente atinge até $10 \mathrm{~m}$ de altura e $60 \mathrm{~cm}$ de diâmetro. Por ser considerada árvore ornamental, é indicada para a arborização de ruas estreitas e sob fios elétricos (LORENZI, 2002).

O branquilho, Gymnanthes klotzschiana Müll.Arg., pertencente à família Euphorbiaceae, é uma planta decídua, heliófita, seletiva higrófita, pioneira, característica e quase exclusiva das florestas aluviais e de galeria ao longo de rios e regatos, principalmente em regiões de altitude (florestas ombrófila mista e estacional semidecídua de altitude). Essa planta espinhenta pode atingir até $12 \mathrm{~m}$ de altura e, tronco com até $50 \mathrm{~cm}$ de diâmetro. Ocorre geralmente em agrupamentos, chegando a formar populações quase puras (LORENZI, 2002). Na referida compilação de pesquisas fitossociológicas no Paraná (SCHEER; BLUM, 2011), essa espécie está apresentada como a arbórea mais abundante para a região da Floresta Ombrófila Mista Aluvial, sendo mensurados aproximadamente 15 vezes mais indivíduos que a segunda colocada, ratificando seu caráter de ótima adaptação e oligodominância nesses ambientes. Lorenzi (2002) destacam o seu valor ecológico para a recuperação de áreas degradadas ao longo de margens de rios e reservatórios, devido à sua tolerância a solos semi-hidromórficos e "hidromórficos".

Luehea divaricata Mart. \& Zucc., conhecida como açoita-cavalo, pertencente à família Malvaceae, é uma espécie arbórea heliófita, secundária ou clímax, tolerante ao sombreamento na fase juvenil. Árvore de caráter decíduo que pode atingir até $30 \mathrm{~m}$ de altura e $100 \mathrm{~cm}$ de diâmetro. Possui tronco tortuoso, nodoso, com reentrâncias e base alargada com sapopemas, ostentando copa larga e densa com folhagem característica (CARVALHO, 2008). Suas características ornamentais, em geral, a recomendam para paisagismo, sendo também muito utilizadas para reflorestamentos em áreas degradadas (LORENZI, 2002). Na compilação de Scheer e Blum (2011) está como o $15^{\circ}$ táxon mais abundante nos estudos realizados na Floresta Ombrófila Mista Montana e em $5^{\circ}$ na Floresta Estacional Semidecidual Submontana do Paraná.

Lafoensia pacari A. St.-Hil., da família Lithraceae, também conhecida como dedaleiro, é uma planta decídua, heliófita, indiferente às condições físicas do solo, característica de florestas de altitude (estacional semidecídua e de ombrófila mista), ocorrendo também no cerrado, porém com menor desenvolvimento (LORENZI, 2002). Atinge até $18 \mathrm{~m}$ de altura e $60 \mathrm{~cm}$ de diâmetro. Por suas características ornamentais é bastante utilizada no paisagismo e arborização urbana. Lorenzi (2002) a recomenda ainda para reflorestamentos mistos na recomposição de áreas degradadas e Carvalho (2003) para recomposição de mata ciliar em locais bem drenados ou com inundações periódicas de rápida duração.

Considerando a dificuldade de informações sobre o desempenho de espécies arbóreas nativas da Floresta Ombrófila Mista Montana/Aluvial no Paraná plantadas em “áreas empréstimo" reconformadas, o presente estudo teve o objetivo de avaliar o crescimento inicial das espécies acima descritas, submetidas a diferentes níveis de calagem e de adubação com NPK, de forma a obtenção de seus potenciais de uso na aceleração do processo de recuperação da vegetação.

\section{MATERIAL E MÉTODOS}

O experimento foi conduzido entre janeiro de 2008 e janeiro de 2010, no município de Piraquara, Paraná.

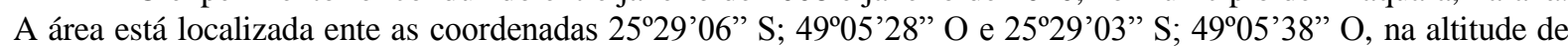
900 m s.n.m.. Segundo classificação climática de Köppen, o clima da região é Cfb, com temperatura média anual entre 12 e $20^{\circ} \mathrm{C}$ e com precipitação anual média entre 1450 e $1500 \mathrm{~mm}$ (CAVIGLIONE et al., 2000).

$\mathrm{O}$ experimento foi estabelecido em uma área de empréstimo de material (argila 1:1) para utilização na construção da barragem Piraquara II. Portanto, os horizontes superficiais e subsuperficiais de área da pesquisa, originalmente coberta por Floresta Ombrófila Mista Montana, foram retirados. Após a extração, a área (com horizonte $\mathrm{C} / \mathrm{CR}$ remanescente), foi reconformada em bancadas e terraços para promover melhor 
condução/infiltração das águas pluviais, mitigando os efeitos dos processos erosivos. Após isso, foi recapeada com $20 \mathrm{~cm}$ de horizonte A proveniente de Gleissolo Melânico, tendo suas propriedades químicas descritas, conforme a tabela 1. Posteriormente foi semeada a gramínea Paspalum notatum Flüggé (pensacola ou grama batatais) de forma a proteger o solo exposto. A pesquisa foi em cima desses procedimentos padrões da empreiteira responsável pela estabilização das áreas de empréstimo usadas na obra. Somente a partir daí, a equipe de pesquisa interviu no processo, estabelecendo o delineamento do experimento, a escolha das espécies e dos níveis de adubação e calagem adiante descritos.

Tabela 1. Propriedades químicas do solo onde foi realizado o experimento.

Table 1. Chemical properties of soil where the experiment was conducted.

\begin{tabular}{|c|c|c|c|c|c|c|c|c|c|c|c|c|c|c|c|}
\hline \multirow[b]{2}{*}{ Amostras } & pH & C & $\mathbf{P}$ & $\mathbf{K}$ & $\mathbf{C a}$ & $\mathbf{M g}$ & Al & $\mathbf{H}+\mathbf{A l}$ & SB & $\mathbf{T}$ & $\mathbf{V}$ & $\mathbf{m}$ & Areia & Silte & Argila \\
\hline & $\mathrm{CaCl}_{2}$ & $\underset{3}{g \mathbf{d m}^{-}}$ & $\underset{\mathbf{d m}^{-3}}{\mathbf{m g}}$ & \multicolumn{7}{|c|}{$\mathrm{cmol}_{\mathrm{c}} \mathrm{dm}^{-3}$} & \multicolumn{2}{|c|}{$\%$} & & $\%$ & \\
\hline $\begin{array}{l}\text { Horizonte A de } \\
\text { recapeamento }\end{array}$ & 4,4 & 13,8 & 1,5 & 0,04 & 0,5 & 0,8 & 2,0 & 9,7 & 1,3 & 11,0 & 11,8 & 60,6 & 24,4 & 16,3 & 59,3 \\
\hline Horizonte $\mathrm{C}$ do local & 4,4 & 1,1 & 1,9 & 0,01 & 0,2 & 0,3 & 2,1 & 7,2 & 0,5 & 7,7 & 6,9 & 79,8 & 28,9 & 45,3 & 25,8 \\
\hline
\end{tabular}

Foram testados três níveis de NPK na formulação 5-20-10 (formulação com alta proporção de P e facilmente encontrada no mercado) e dois níveis de calagem, com uso de calcário dolomítico, com $75 \%$ de PRNT), totalizando seis tratamentos (Tabela 2). A dose zero de calcário não foi considerada, devido ao resultado das análises de $\mathrm{pH}$ do solo (Tabela 1), ter mostrado haver a necessidade de pequena elevação para seguir recomendações da literatura (CARNEIRO et al., 2009). Portanto, considerando-se o exposto e a baixa disponibilidade de nutrientes no solo (Tabela 2), mesmo tratando-se de espécies nativas, este tratamento não foi apresentado no presente estudo.

Tabela 2. Tratamentos utilizados no experimento com suas respectivas doses de NPK e calcário.

Table 2. Treatments used in the experiment with their respective NPK and limestone doses.

\begin{tabular}{ccc}
\hline Tratamentos & NPK 5-20-10 (g/cova) & Calcário (g/cova) \\
\hline T1 & 0 & 250 \\
T2 & 0 & 500 \\
T3 & 300 & 250 \\
T4 & 300 & 500 \\
T5 & 500 & 250 \\
T6 & 500 & 500 \\
\hline
\end{tabular}

Foram utilizadas quatro espécies arbóreas: Schinus terebinthifolius, Luehea divaricata, Gymnanthes klotzschiana e Lafoensia pacari. As mudas dessas quatro espécies foram produzidas em viveiro da Companhia de Saneamento do Paraná (SANEPAR), a partir de sementes em tubetes de polipropileno com capacidade volumétrica de $110 \mathrm{~cm}^{3}$. As mudas foram semeadas em substrato comercial à base de casca de Pinus e vermiculita e adubadas com a dose de $2,7 \mathrm{~g} \mathrm{dm}^{-3}$ de fertilizante granulado $\left(\mathrm{N} ; \mathrm{P}_{2} \mathrm{O}_{5} ; \mathrm{K}_{2} \mathrm{O}\right.$, formulação 15-9-12) de liberação lenta (5-6 meses), tempo de liberação suficiente para o tempo da muda no viveiro. A irrigação no viveiro foi realizada duas vezes por dia por microaspersores, sendo uma pela manhã e outra à tarde, tanto no período de casa de vegetação quanto na área para rustificação das mudas.

No campo, o plantio das mudas, com altura entre $40-50 \mathrm{~cm}$ e idade entre 8 e 12 meses, foi realizado em covas abertas manualmente com dimensões $30 \times 30 \times 30 \mathrm{~cm}$. O calcário foi incorporado nas covas 20 dias antes do plantio e a adubação foi realizada no dia do plantio de acordo com os tratamentos. As mudas foram plantadas em janeiro de 2008, com espaçamento de $2 \mathrm{~m}$ entre plantas e dispostas em linhas. Quinze dias após o plantio foi realizada uma adubação de cobertura, em todas as plantas do experimento, com uréia $\left(\mathrm{NH}_{2}\right)_{2} \mathrm{CO}$ na proporção de $50 \mathrm{~g} /$ cova, conforme recomendado por Carneiro et al. (2009).

Ao atingirem dois anos de idade no campo (aproximadamente três anos após a germinação), os indivíduos foram mensurados para a obtenção das variáveis altura e diâmetro à altura da base (colo). A altura foi medida com uma régua graduada e o diâmetro com um paquímetro digital $(0,01 \mathrm{~mm})$. As médias de cada tratamento dessas variáveis foram compostas por três repetições, cada uma composta de pelo menos 3 plantas sadias, não considerando as de bordadura e as danificadas. A opção por utilizar para a composição das médias somente das mudas em boas condições deveu-se ao fato de que, na região do estudo, plantios de mudas nativas provenientes de tubetes em escala de campo apresentam altas taxas de mortalidade, devido diversos fatores

FLORESTA, Curitiba, PR, v. 47, n. 3, p. 279 - 287, jul. / set. 2017

Scheer, M. B. et al.

ISSN eletrônico 1982-4688

DOI: $10.5380 /$ rf.v47i1.41973 
ambientais, tais como geadas, períodos de secas de encharcamento de covas, ataques frequentes de formigas, etc., o que, geralmente, não ocorre em experimentos em casa de vegetação. Com isso reduziu-se significativamente estas possíveis interferências na composição das médias, tendo-se como resultado os potenciais de crescimento das espécies nas condições do estudo. O experimento foi conduzido em delineamento inteiramente casualizado em arranjo fatorial 2 × 3 ( 2 níveis de calcário e 3 níveis de fertilizante NPK).

Após a verificação da homogeneidade das variâncias e outras condicionantes através do teste de Bartlett, foram realizadas análise de variância e testes de Tukey a 5\% de probabilidade. Os efeitos dos níveis de fertilizante (fator quantitativo) foram avaliados através de regressões polinomiais em função das doses de calcário utilizadas.

Além disso, equações de regressão foram ajustadas usando-se os níveis de fertilizante utilizados com o intuito de se obter a dose recomendada de NPK, levando em consideração a dose de calcário, capaz de promover o maior crescimento, tanto para altura quanto para diâmetro, das quatro espécies testadas no experimento.

\section{RESULTADOS E DISCUSSÃO}

Observando-se o crescimento das espécies utilizadas no experimento, percebe-se que os maiores e menores valores em altura foram obtidos por S. terebinthifolius, sendo estatisticamente diferentes das demais pelo teste de Tukey a $5 \%$ de probabilidade (Figura 1).

A

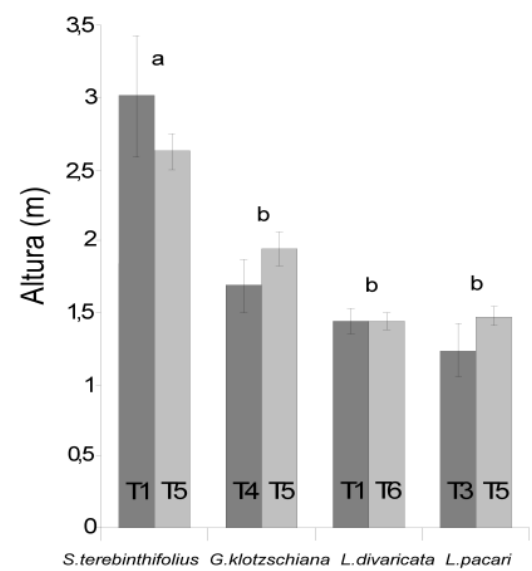

b

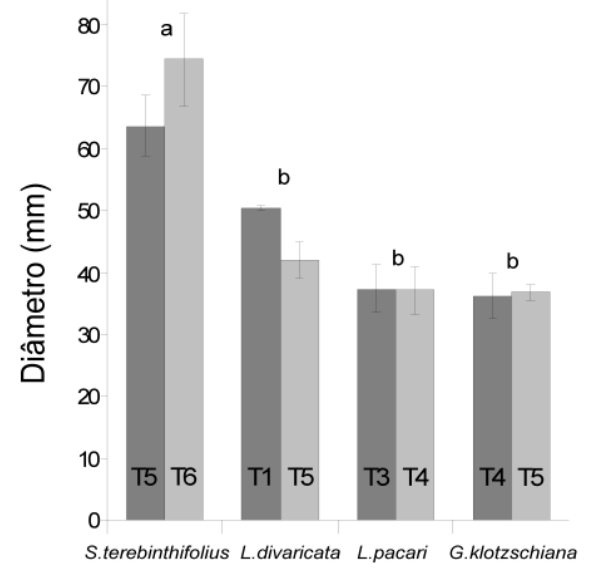

Figura 1. Alturas e diâmetros obtidos para as quatro espécies testadas ${ }^{1 .}$

Figure 1. Heights and diameters for the four species tested.

${ }^{1}$ Barras seguidas pela mesma letra minúscula não diferem entre si, estatisticamente, pelo teste de Tukey a 5\% de probabilidade. As linhas verticais referem-se aos erros-padrão. $\mathrm{T}=$ tratamentos com os melhores resultados, conforme Tabela 2.

As outras três espécies obtiveram valores consideravelmente menores. Dentre essas três, a que apresentou valores mais elevados para altura foi G. klotzchiana e para diâmetro foi L. divaricata, porém não diferindo estatisticamente das demais (Figura 1).

$\mathrm{O}$ maior crescimento para altura e diâmetro observado em S. terebinthifolius, em detrimento às demais espécies, provavelmente ocorreu pelo fato desta ser uma espécie pioneira ou uma secundária inicial com maior plasticidade fenotípica (CHIAMOLERA et al., 2011), apresentando-se em diversas formações fitogeográficas, desde restingas, até formações de florestas ombrófilas (densa e mista) e estacionais, demonstrando também maior tolerância no ambiente avaliado. G. klotzschiana, espécie do mesmo nível sucessional que $S$. terebinthifolius, também apresentou resultados satisfatórios de crescimento, porém bem inferiores aos observados para S. terebinthifolius.

Entre os tratamentos com $250 \mathrm{~g}$ de calcário, os maiores valores observados para a altura de $S$. terebinthifolius foram tanto para o menor nível de fertilizante $(0 \mathrm{~g})$, quanto para o maior $(500 \mathrm{~g})$, sendo que este último não difere estatisticamente do nível intermediário de fertilizante $(300 \mathrm{~g})$. Os tratamentos com $500 \mathrm{~g}$ de calcário indicaram maiores alturas com o aumento das doses de fertilizante (Tabela 3).

Os níveis de calcário só diferiram na dose $0 \mathrm{~g}$ de fertilizante, sendo que o nível mais alto de calcário resultou em valores baixos para ambas as variáveis (altura e diâmetro), indicando, provavelmente um desequilíbrio nutricional $(\mathrm{Ca}$ e $\mathrm{Mg})$. Resultados positivos para o crescimento de $S$. terebinthifolius submetida à calagem e fertilização NPK foram observados por Croce (2005), Sousa et al. (2006) e Souza et al. (2006). 
Tabela 3. Médias ${ }^{1}$ e erros-padrão para alturas e diâmetros de colo de Schinus terebinthifolius, nos três níveis de fertilizante e dois níveis de calcário testados, $\mathrm{n}=3$.

Table 3. Averages and standard errors for heights and stem diameters of Schinus terebinthifolius on three levels of fertilizer and two levels of limestone tested, $\mathrm{n}=3$.

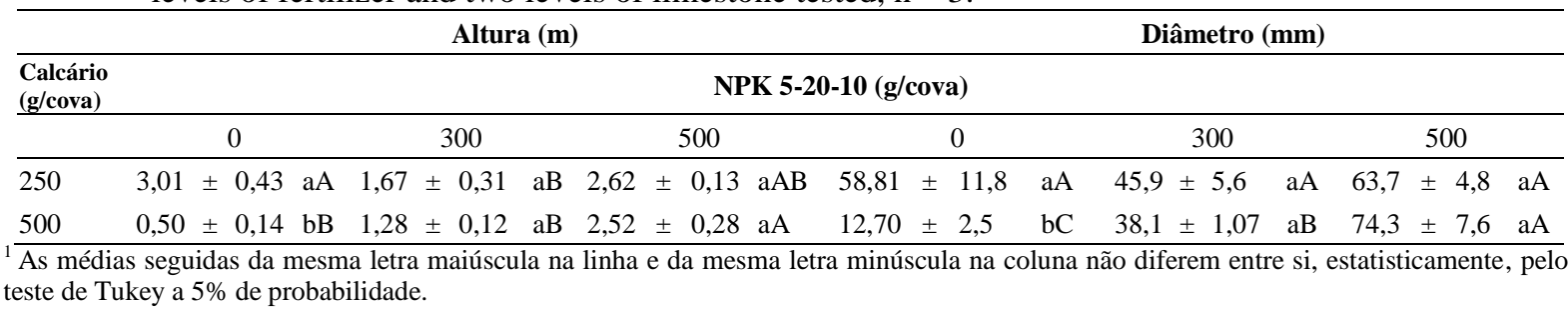

Para G. klotzschiana não foi verificada interação entre os fatores calagem e fertilização para as variáveis mensuradas (Tabela 4). Para a variável altura foi possível a obtenção de médias de 58 a $70 \%$ superiores, respectivamente para os níveis 300 e $500 \mathrm{~g}$ de fertilizante, dado que estes dois níveis não diferiram estatisticamente entre si (Tabela 4). Apesar de não existir diferenças para níveis de calagem, o diâmetro apresentou resposta positiva à fertilização (Tabela 4), sendo estimada por exemplo, por meio de regressão, com o uso de $250 \mathrm{~g}$ de calcário, a dose de 319 g de NPK 5-20-10 por cova para obtenção de máximo diâmetro de colo (36 mm) aos 2 anos de plantio no campo (Tabela 7). Estudos sobre G. klotzschiana são raros na literatura (GOMES et al. 2008).

Tabela 4. Médias ${ }^{1}$ e erros-padrão para alturas e diâmetros de colo de Gymnanthes klotzschiana, nos três níveis de fertilizante e dois níveis de calcário testados, $\mathrm{n}=3$.

Table 4. Averages and standard errors for heights and stem diameters of Gymnanthes klotzschiana on three levels of fertilizer and two levels of limestone tested, $n=3$.

\begin{tabular}{|c|c|c|c|c|c|c|c|c|c|c|}
\hline \multirow{3}{*}{$\begin{array}{l}\begin{array}{l}\text { Calcário } \\
\text { (g/cova) }\end{array} \\
\end{array}$} & \multicolumn{6}{|c|}{ Altura (m) } & \multicolumn{4}{|c|}{ Diâmetro (mm) } \\
\hline & \multicolumn{10}{|c|}{ NPK 5-20-10 (g/cova) } \\
\hline & & 0 & & 300 & 500 & $\begin{array}{l}\text { Médi } \\
\text { a }\end{array}$ & 0 & 300 & 500 & Média \\
\hline 250 & 1,32 & \pm & 0,23 & $1,43 \pm 0,16$ & $1,95 \pm 0,12$ & $1,56 \mathrm{a}$ & $24,56 \pm 5,36$ & $\frac{32,0}{6} \pm 4,14$ & $36,74 \pm 1,43$ & $31,12 \mathrm{a}$ \\
\hline 500 & 0,63 & \pm & 0,18 & $1,69 \pm 0,19$ & $1,43 \pm 0,18$ & $1,26 \mathrm{a}$ & $11,65 \pm 1,57$ & $\frac{36,1}{7} \pm 3,55$ & $28,33 \pm 2,17$ & $25,38 \mathrm{a}$ \\
\hline Média & & ,99H & & $1,56 \mathrm{~A}$ & $1,69 \mathrm{~A}$ & & $18,11 \mathrm{~B}$ & $34,12 \mathrm{~A}$ & $32,53 \mathrm{~A}$ & \\
\hline
\end{tabular}

$1 \frac{1}{\text { As médias seguidas da mesma letra, maiúscula na linha e minúscula na coluna, não diferem entre si estatisticamente, pelo teste de Tukey a }}$ $5 \%$ de probabilidade.

Para a variável altura de $L$. divaricata não houve interação entre os fatores calcário e NPK (Tabela 5). A espécie apresentou, para a variável altura, a maior média com o uso de $500 \mathrm{~g}$ de NPK, porém, estatisticamente semelhante à obtida sem a adição de fertilizante (Tabela 5).

Tabela 5. Médias ${ }^{1}$ e erros-padrão para alturas e diâmetros de Luehea divaricata, nos três níveis de fertilizante e dois níveis de calcário testados, $\mathrm{n}=3$

Table 5. Averages and standard errors for heights and diameters of Luehea divaricata on three levels of fertilizer and two levels of limestone tested, $n=3$.

\begin{tabular}{|c|c|c|c|c|c|c|c|c|c|c|}
\hline \multicolumn{11}{|c|}{ Altura (m) } \\
\hline Calcário $(\mathrm{g} /$ cova $)$ & \multicolumn{10}{|c|}{ NPK 5-20-10 (g/cova) } \\
\hline & \multicolumn{3}{|c|}{0} & \multicolumn{3}{|c|}{300} & \multicolumn{3}{|c|}{500} & Média \\
\hline 250 & 1,45 & \pm & 0,09 & 1,01 & \pm & 0,17 & 1,38 & \pm & 0,23 & $1,28 \mathrm{a}$ \\
\hline 500 & 0,92 & \pm & 0,19 & 0,91 & \pm & 0,06 & 1,45 & \pm & 0,06 & $1,09 \mathrm{a}$ \\
\hline Média & \multicolumn{3}{|c|}{$1,19 \mathrm{AB}$} & \multicolumn{3}{|c|}{$0,96 \mathrm{~B}$} & \multicolumn{3}{|c|}{$1,41 \mathrm{~A}$} & \\
\hline \multicolumn{11}{|c|}{ Diâmetro (mm) } \\
\hline \multirow[t]{2}{*}{ Calcário $(\mathrm{g} /$ cova $)$} & \multicolumn{10}{|c|}{ NPK 5-20-10 (g/cova) } \\
\hline & \multicolumn{3}{|c|}{0} & \multicolumn{3}{|c|}{300} & \multicolumn{4}{|c|}{500} \\
\hline 250 & 50,4 & $\pm 0,19$ & $\mathrm{aA}$ & & $2,47 \pm$ & $\pm 3,83 \quad \mathrm{aB}$ & & 42,01 & $\pm 2,98$ & $\mathrm{aAB}$ \\
\hline 500 & 27,3 & $\pm 5,89$ & $\mathrm{bA}$ & & $8,45 \pm$ & $\pm 1,04$ aA & & 37,43 & $\pm 4,05$ & $\mathrm{aA}$ \\
\hline
\end{tabular}

FLORESTA, Curitiba, PR, v. 47, n. 3, p. 279 - 287, jul. / set. 2017

Scheer, M. B. et al.

ISSN eletrônico 1982-4688

DOI: $10.5380 /$ rf.v47i1.41973 
${ }^{1}$ As médias seguidas da mesma letra maiúscula na linha e da mesma letra minúscula na coluna não diferem entre si, estatisticamente, pelo teste de Tukey a $5 \%$ de probabilidade.

Para o crescimento em diâmetro de L. divaricata, o melhor resultado foi observado no tratamento sem a adição de fertilizante e com a menor dose de calcário, valor este 55,4\% maior ao observado no tratamento com $300 \mathrm{~g}$ de NPK e $250 \mathrm{~g}$ de calcário, conforme demonstrado na Tabela 6. Somente para o nível 0 g de fertilizante foram obtidas diferenças estatisticamente significativas entre os dois níveis de calcário, sendo que o menor nível apresentou média cerca de $85 \%$ superior (Tabela 5).

Os valores de crescimento em altura e diâmetro apresentados neste experimento são similares aos obtidos por Moreira (2004) e muito superiores aos observados por Sousa et al. (2006) e Sousa et al. (2007), todos em experimentos conduzidos em áreas degradadas.

Não houve interação entre os fatores (calcário e fertilizante) para a variável altura de L. pacari (Tabela 6). Conforme esperado, ambas as doses de 300 e $500 \mathrm{~g}$ de NPK promoveram melhores resultados em altura do que sem a aplicação de fertilizante, sendo até $57 \%$ maior do que com o nível $0 \mathrm{~g}$ de NPK (Tabela 6). Tendo por base o efeito do calcário, a dose de $250 \mathrm{~g}$ possibilitou um maior crescimento, sendo sua média superior em cerca de $60 \%$ ao valor do obtido com $500 \mathrm{~g}$ de calcário por cova (Tabela 6).

Tabela 6. Médias ${ }^{1}$ e erros-padrão para alturas e diâmetros de Lafoensia pacari, nos três níveis de fertilizante e dois níveis de calcário testados, $\mathrm{n}=3$.

Table 6. Averages and standard errors for Heights and diameters of Lafoensia pacari on three levels of fertilizer and two levels of limestone tested, $\mathrm{n}=3$.

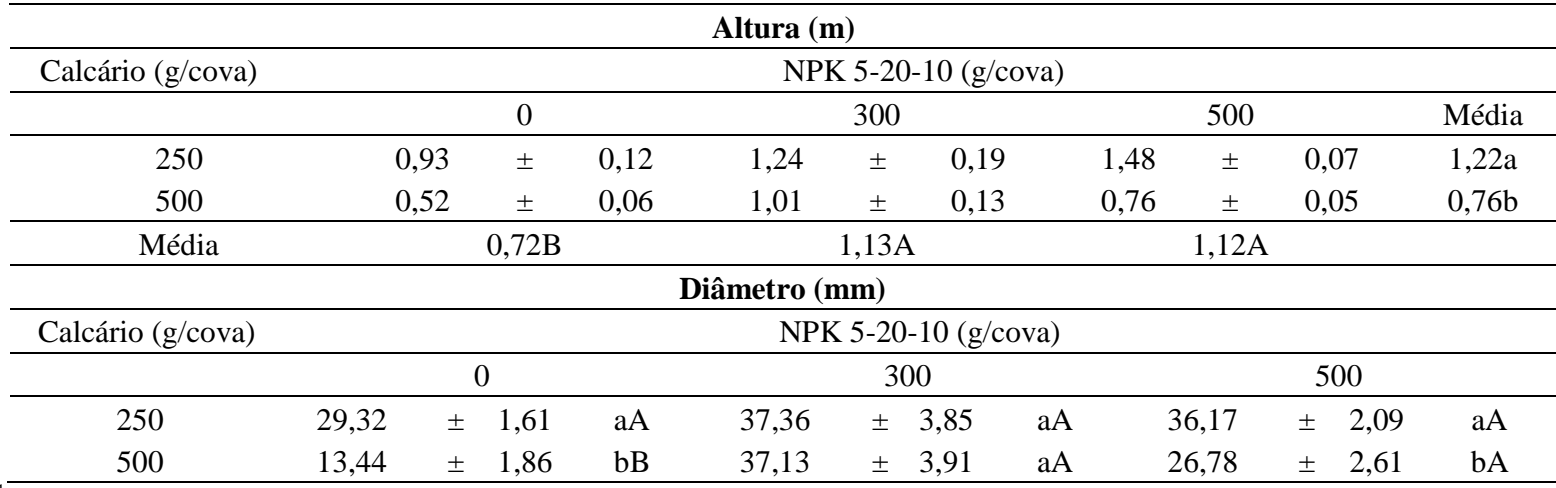

1 As médias seguidas da mesma letra, maiúscula na linha e minúscula na coluna, não diferem entre si estatisticamente, pelo teste de Tukey a $5 \%$ de probabilidade.

Para diâmetro, todos os níveis de fertilizante e calcário não diferiram estatisticamente, exceto o nível 0 $\mathrm{g}$ de fertilizante e $500 \mathrm{~g}$ de calcário (Tabela 6). Exceto para o nível $300 \mathrm{~g}$ de NPK, os demais resultados apontam valores estatisticamente superiores usando o menor nível de calagem testado ( $250 \mathrm{~g})$. Um maior crescimento das variáveis altura e diâmetro para Lafoensia pacari, proporcionado pela maior disponibilização de nutrientes dada pela adubação NPK, foi também observado por Paula (2003) e Santos \& Coelho (2008) para experimentos com adubação orgânica e evidenciado pelo crescimento insatisfatório dado pela ausência de adubação também observado por Chiamolera \& Angelo (2007) e Sousa et al. (2007).

A aplicação de calcário é feita com o intuito de aumentar o pH do solo, a fim de promover uma maior saturação de bases e maior CTC (capacidade de troca catiônica); dessa forma diminuindo a acidez potencial e aumentando a disponibilidade de nutrientes e a atividade microbiana do solo, possibilitando assim um maior crescimento radicial e da parte aérea das plantas (PRADO, 2003). De acordo com Raij (1991) com a calagem ocorre a maior disponibilização de fósforo, havendo estímulos para o aumento do sistema radicial, favorecendo o aproveitamento de água e nutrientes disponíveis no solo, fato também observado por Prado et al. (2004), que relacionaram a proliferação das raízes à precipitação do Al tóxico do solo ocasionada pelo calcário. Por outro lado, o maior crescimento em altura e diâmetro obtido, para a maioria das plantas estudadas no experimento, foi observado com a utilização da menor dose de calcário dolomítico (250 g). A dose superior de calagem (500 g), na grande maioria das vezes, acabou limitando o desenvolvimento das plantas, traduzido em menores valores para as variáveis medidas. Tal comportamento também foi constatado por Rocha et al. (2008) e provavelmente se dá pela diminuição da disponibilidade de micronutrientes ocasionada pela elevação de pH (MALAVOLTA, 2006), o que acabou afetando o crescimento da planta. De acordo com Fernandes et al. (2003) o rendimento máximo que uma planta pode apresentar é obtido com a combinação específica entre as concentrações de 
nutrientes, uma vez que a concentração em excesso de um dado nutriente pode promover um desequilíbrio nutricional, afetando a concentração e/ou absorção de outro.

Para as equações de regressão que puderam explicar a correlação entre as variáveis medidas e as doses crescentes de NPK ( $<<0,05)$, foram determinadas as doses de fertilizantes mais adequadas para prover os maiores valores das variáveis medidas (Tabela 7). No entanto, para algumas equações (S. terebinthifolius $e$ L. divaricata), não foi possível indicar uma dose precisa, mesmo explicando a correlação entre fatores, necessitando-se, provavelmente, de mais repetições e níveis de fertilização NPK para a obtenção dos valores recomendados. Para essas situações e as não significativas, adotou-se como "recomendação" a dose onde foi observado o maior valor mensurado no experimento(Tabela 9).

Tabela 7. Equações de regressão e melhores doses estimadas de fertilizante NPK para diâmetro e altura das quatro espécies avaliadas aos dois anos de plantio em campo.

Table 7. Regression equations and the best estimated doses of NPK fertilizer for diameter and height of four tested species at two years in the field.

\begin{tabular}{|c|c|c|c|c|c|}
\hline Espécie & Característica & $\begin{array}{l}\text { Dose de } \\
\text { Calcário } \\
\text { (g)/cova }\end{array}$ & Equação & $\mathbf{r}^{2}$ & $\begin{array}{c}\text { Dose de NPK } \\
(\text { g/cova)*** }\end{array}$ \\
\hline \multirow{4}{*}{$\begin{array}{l}\text { Schinus } \\
\text { terebinthifolius }\end{array}$} & \multirow{2}{*}{ Diâmetro } & 250 & $y=58,81-0,12201 * x+0,0002634 * x^{2}$ & n.s. & 300 \\
\hline & & 500 & $y=12,7+0,02662 * x+0,0001930 * x^{2}$ & $0,94 * *$ & $>500 ?$ \\
\hline & \multirow{2}{*}{ Altura } & 250 & $\mathrm{y}=3,01-0,01000^{*} \mathrm{x}+0,0000184^{*} \mathrm{x}^{2}$ & n.s. & 300 \\
\hline & & 500 & $y=0,50+0,00043 * x+0,0000071 * x^{2}$ & $0,90 * *$ & $>500 ?$ \\
\hline \multirow{4}{*}{ Luehea divaricata } & \multirow{2}{*}{ Diâmetro } & 250 & $y=50,45-0,12458 * x+0,0002154 * x^{2}$ & $0,77 *$ & 0 \\
\hline & & 500 & $y=27,32-0,02086 * x+0,0000821 * x^{2}$ & n.s. & 300 \\
\hline & \multirow{2}{*}{ Altura } & 250 & $y=1,45-0,00344 * x+0,0000066^{*} x^{2}$ & n.s. & 0 \\
\hline & & 500 & $\mathrm{y}=0,92-0,00164 * x+0,0000054 * x^{2}$ & $0,69 *$ & $>500 ?$ \\
\hline \multirow{4}{*}{$\begin{array}{l}\text { Gymnanthes } \\
\text { klotzschiana }\end{array}$} & \multirow{2}{*}{ Diâmetro } & 250 & $y=24,56+0,02595 * x-0,0000032 * x^{2}$ & n.s. & 300 \\
\hline & & 500 & $y=11,65+0,15431 * x-0,0002418^{*} x^{2}$ & $0,85^{* *}$ & 319 \\
\hline & \multirow{2}{*}{ Altura } & 250 & $y=1,32-0,00093^{*} x+0,0000043^{*} x^{2}$ & n.s. & 300 \\
\hline & & 500 & $\mathrm{y}=0,66+0,00625^{*} \mathrm{x}-0,0000094^{*} \mathrm{x}^{2}$ & $0,67 *$ & 332 \\
\hline \multirow{4}{*}{ Lafoensia pacari } & \multirow{2}{*}{ Diâmetro } & 250 & $\mathrm{y}=29,31+0,04647 * x-0,0000655 * x^{2}$ & n.s. & 300 \\
\hline & & 500 & $y=13,44+0,15737 * x-0,0002614 * x^{2}$ & $0,84 * *$ & 301 \\
\hline & \multirow{2}{*}{ Altura } & 250 & $\mathrm{y}=0,93+0,00093 * \mathrm{x}+3,3333 \mathrm{e}^{-7} * \mathrm{x}^{2}$ & n.s. & 300 \\
\hline & & 500 & $y=0,52+0,00339 * x-0,0000058^{*} x^{2}$ & $0,73 *$ & 292 \\
\hline
\end{tabular}

n.s. = não significativo; $*$ = significativo a $5 \%$ de probabilidade; $* *=$ significativo a $1 \%$ de probabilidade.

*** Dose de NPK 5-20-10 com o melhor resultado medido ou obtida a partir da regressão.

\section{CONCLUSÕES}

- A dose de $500 \mathrm{~g}$ de calcário, em alguns tratamentos para S. terebinthifolius e L. pacari, afetou negativamente o desenvolvimento das plantas. Isto, provavelmente está relacionado ao aumento excessivo do $\mathrm{pH}$ e consequente diminuição da disponibilidade de micronutrientes ou ao desbalanço nutricional ocasionado, embora o trabalho não tenha avaliado esse efeito.

- Exceto para L. divaricata, de um modo geral as espécies testadas responderam positivamente à adição de fertilizante, apresentando resultados melhores que os obtidos sem sua utilização.

- Todas as espécies estudadas apresentaram desenvolvimento satisfatório nas condições do experimento, apresentando potenciais, juntamente com outras práticas, de serem usadas para plantios em solos antropizados, como os do presente estudo. S. terebinthifolius foi a espécie que apresentou diâmetros de colo e alturas consideravelmente superiores as demais.

\section{REFERÊNCIAS}

ALVES, M. C.; NASCIMENTO, V.; SOUZA, Z. M. Recuperação de área de empréstimo usada para construção de hidrelétrica. Revista Brasileira de Engenharia Agrícola e Ambiental, Campina Grande, v. 16, n. 8, p. 887893, 2012.

CARNEIRO, C.; SCHEER, M. B.; CUNHA, F.; ANDREOLI, C. V. Manual técnico para implantação de

FLORESTA, Curitiba, PR, v. 47, n. 3, p. 279 - 287, jul. / set. 2017

Scheer, M. B. et al.

ISSN eletrônico 1982-4688

DOI: $10.5380 /$ rf.v47i1.41973 
cortinas verdes e outros padrões vegetais em estações de tratamento de esgoto. Curitiba: SANEPAR, v. 1, 1 ed. 2009, 109p.

CARVALHO, P. E. R. Espécies arbóreas brasileiras. Curitiba: EMBRAPA - CNPF/SPI, v. 1, 2003. 1039p.

CARVALHO, P. E. R. Açoita-Cavalo (Luehea divaricata). Colombo: EMBRAPA-CNPF, 2008. (Circular Técnica, 147).

CAVIGLIONE, J. H.; KIIHL, L. R. B.; CARAMORI, P.H.; OLIVEIRA, D. Cartas climáticas do Paraná. Londrina: Instituto Agronômico do Paraná (IAPAR), 2000 (CDROM).

CHIAMOLERA, L. B.; ANGELO, A. C. Resposta de espécies nativas em áreas com diferentes graus de sucessão. Revista Brasileira de Biociências, Porto Alegre, v. 5, p. 132-134, suplemento 1, 2007.

CHIAMOLERA, L. B.; ANGELO, A. C.; BOEGER, M. R. Crescimento e sobrevivência de quatro espécies florestais nativas plantadas em áreas com diferentes estágios de sucessão no reservatório Iraí-PR. Revista Floresta, Curitiba, v. 41, n. 4, p. 765-778, 2011.

COSTA FILHO, R. T. da. Crescimento de mudas de Mimosa caesalpiniifolia Benth. e Astronium fraxinifolium Schott em resposta à calagem e adubação fosfatada. 2010. 48f. Tese (Doutorado em Produção Vegetal) - Faculdade de Ciências Agrárias e Veterinárias, Universidade Estadual Paulista, Jaboticabal, 2010.

CROCE, C. G. G. Desenvolvimento inicial de duas espécies arbóreas nativas e pioneiras sob tratamentos convencional, orgânico e biodinâmico. 2005. 49f. Dissertação (Mestrado em Agronomia) - Faculdade de Ciências Agronômicas, Universidade Estadual Paulista, Botucatu, 2005.

FERNANDES, A. R.; CARVALHO, J. G. de; MELO, P. C. Efeito do fósforo e do zinco sobre o crescimento de mudas do cupuaçuzeiro (Theobroma grandiflorum Schum.). Cerne, Lavras, v. 9, n. 2, p. 221-230, 2003.

GOMES, J. F.; LONGHI, S. J.; ARAÚJO, M. M. A.; BRENA, D. A. Classificação e crescimento de unidades de vegetação em floresta ombrófila mista, São Francisco de Paula, RS. Ciência Florestal, Santa Maria, v. 18, n. 1, p. 93-107, 2008.

LORENZI, H. Árvores brasileiras: manual de identificação e cultivo de plantas arbóreas do Brasil. 4. ed. Nova Odessa: Editora Plantarum, v. 1, 2002, 368p.

MALAVOLTA, E. Manual de nutrição mineral de plantas. São Paulo: Agronômica Ceres, 2006, 638p.

MOREIRA, P. R. Manejo do solo e recomposição da vegetação com vistas a recuperação de áreas degradadas pela extração de bauxita, Poços de Caldas, MG. 2004. 139f. Tese (Doutorado em Ciências Biológicas) - Instituto de Biociências, Universidade Estadual Paulista, Rio Claro, 2004.

PAULA, M. B. R. M. A adubação e época de plantio em mangava brava (Lafoensia pacari St. Hil.) Lythraceae. 2003. 54f. Dissertação (Mestrado em Agricultura Tropical) - Faculdade de Agronomia e Medicina Veterinária, Universidade Federal de Mato Grosso, Cuiabá, 2003.

PRADO, R. M. Efeito da calagem no desenvolvimento, no estado nutricional e na produção de frutos da goiabeira e da caramboleira. 2003. 68f. Tese (Doutorado) - Faculdade de Ciências Agrárias, Universidade Estadual Paulista, Jaboticabal, 2003.

PRADO, R. M.; NATALE, W.; CORRÊA, M. C. M; BRAGHIROLLI, L. F. Efeitos da aplicação de calcário no desenvolvimento, no estado nutricional e na produção de matéria seca de mudas de maracujazeiro. Revista Brasileira de Fruticultura, Jaboticabal, v. 26, n. 1, p. 145-149, 2004.

ROCHA, J. B. O.; POZZA, A. A. A.; CARVALHO, J. G.; SILVA, C. A.; CURI, N. Efeito da calagem na nutrição mineral e no crescimento inicial do eucalipto a campo em Latossolo húmico da Zona da Mata (MG). Scientia Forestalis, Piracicaba, v. 36, n. 80, p. 255-263, 2008.

SANTOS, L. W.; COELHO, M. F. B. Cobertura verde e uso de resíduo orgânico em Lafoensia pacari A.St.- Hil. Revista Brasileira de Plantas Medicinais, Botucatu, v. 10, n. 3, p. 16-23, 2008.

SCHEER, M. B; BLUM, C. T. Arboreal Diversity of the Atlantic Forest of Southern Brazil: From the Beach Ridges to the Paraná River, The Dynamical Processes of Biodiversity - Case Studies of Evolution and Spatial Distribution, PhD. Oscar Grillo (Ed.), InTech, DOI: 10.5772/24129. Disponível em: http://www.intechopen.com/books/the-dynamical-processes-of-biodiversity-case-studies-of-evolution-and- 
spatial-distribution/arboreal-diversity-of-the-atlantic-forest-of-southern-brazil-from-the-beach-ridges-to-theparana-riv, 2011.

SOUSA, L. P.; CURCIO, G. R.; DEDECEK, R. A.; WENDLING, I.; LAVORANTI, O. J. Avaliação do crescimento de espécies arbóreas nativas em solo reconstituído e compactado: Rodovia BR-277, Porto Amazonas, PR. Boletim de Pesquisa e Desenvolvimento, Colombo, n. 30, 2006.

SOUSA, L. P.; ANGELO, A. C.; CURCIO, G. R.; BONNET, A.; GALVÃO, F. Recuperação ambiental em áreas de estepe do Primeiro Planalto Paranaense, mediante plantio de espécies arbóreas. Pesquisa Florestal Brasileira, Colombo, n. 55, p. 95-101, 2007.

SOUZA, C. A. Z.; OLIVEIRA, R. B.; MARTINS FILHO, S.; LIMA, J. S. S. Crescimento em campo de espécies florestais em diferentes condições de adubações. Ciência Florestal, Santa Maria, v. 16, n. 3, p. 243-249, 2006.

VAN RAIJ, B. Fertilidade do solo e adubação. São Paulo: Agronômica Ceres; Piracicaba: POTAFOS, 1991, $343 p$

FLORESTA, Curitiba, PR, v. 47, n. 3, p. 279 - 287, jul. / set. 2017 